\title{
VICTOR KOKAY, La pensée de Schopenhauer dans l'œuvre de Paul Valéry
}

\section{Fabio Scotto}

\section{OpenEdition}

\section{Journals}

\section{Edizione digitale}

URL: https://journals.openedition.org/studifrancesi/23037

DOI: 10.4000/studifrancesi.23037

ISSN: 2427-5856

\section{Editore}

Rosenberg \& Sellier

\section{Edizione cartacea}

Data di pubblicazione: 1 avril 2020

Paginazione: 211-212

ISSN: 0039-2944

\section{Notizia bibliografica digitale}

Fabio Scotto, «victor кокау, La pensée de Schopenhauer dans l'œuvre de Paul Valéry», Studi Francesi [Online], 190 (LXIV | I) | 2020, online dal 01 mai 2020, consultato il 02 août 2021. URL: http:// journals.openedition.org/studifrancesi/23037 ; DOI: https://doi.org/10.4000/studifrancesi.23037

Questo documento è stato generato automaticamente il 2 août 2021.

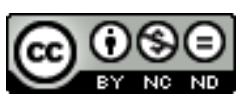

Studi Francesi è distribuita con Licenza Creative Commons Attribuzione - Non commerciale - Non opere derivate 4.0 Internazionale. 


\title{
VICTOR KOKAY, La pensée de Schopenhauer dans l'œuvre de Paul Valéry
}

\author{
Fabio Scotto
}

\section{NOTIZIA}

VICTOR KOKAY, La pensée de Schopenhauer dans l'œuvre de Paul Valéry, Paris, L'Harmattan, 2018, «Approches littéraires», 264 pp.

1 L'Autore, professore di francese all'Université St. Francis Xavier in Canada, raccoglie in questo volume una serie di studi volti a mostrare una filiazione schopenhaueriana del pensiero di Paul Valéry. Nell'«Introduction» (pp. 9-20), Kokay rileva come nel dibattito critico tale argomentazione, pur se non del tutto elusa, non sia stata mai davvero approfonditamente considerata, avendo per lo più i critici ritenuto la frequentazione dei testi di Schopenhauer ad opera di Valéry un esercizio giovanile. Se sono note le letture filosofiche di Valéry, da Descartes a Kant e a Nietzsche, tuttavia non è mai emersa in modo chiaro e condiviso una tributarietà esplicita di alcune sue idee dall'opera del filosofo tedesco, che egli lesse, come attestano inequivocabilmente una sua lettera indirizzata a Gide nel 1891 e taluni rimandi presenti nei suoi Cahiers I, III e IV.

2 Victor Kokay si propone quindi nel suo volume di andare in controtendenza rispetto a questa doxa critica e di mostrare invece, partendo da un confronto dei testi dei due autori, una a suo avviso sicura presenza dell'influsso di Schopenhauer sui testi del poeta di Sète, in particolare per quanto riguarda i concetti di coscienza, d'immagine e di rappresentazione, poi riconducibili, nella sua analisi, alla nozione di «Moi pur», assai dibattuta e più esplicitamente presente nella stagione delle sue letture schopenhaueriane. 
3 Articolato in tre parti seguite da una «Conclusion», il saggio dà conto nella prima, intitolata «Schopenhauer par lui-même» (pp. 21-55), delle linee principali di sviluppo della filosofia di Schopenhauer, con particolare riferimento alle idee di rappresentazione e volontà che diedero il titolo a una delle sue opere maggiori (Il mondo come volontà e rappresentazione, 1819); qui si sottolinea come la conoscenza avvenga attraverso la rappresentazione che presuppone un'interdipendenza di soggetto e oggetto, se essa è determinata dalla soggettività che nella percezione esperisce l'oggetto, che perciò esiste, mentre la volontà coincide con la vita stessa del mondo. Inoltre, viene illustrata l'idea di bellezza e arte del filosofo tedesco intesa come contemplazione della cosa in sé che supera l'individualità del soggetto esperente. Il genio percepisce il mondo come oggetto e lo riflette e la libertà manifesta il desiderio che ha la volontà del soggetto di ricercare un modo di affrancarsi dalla necessità.

Nella seconda parte, «Schopenhauer dans les Cahiers de Valéry» (pp. 57-169), l'A. entra nel vivo del confronto individuando negli anni attorno al 1890, a un livello iniziale, poi, in modo più specifico e approfondito, attraverso la mediazione di Nietzsche, verso il 1901-1902, poi ancora nel 1904-1905 e tra il 1913 e il 1915 i periodi nei quali Valéry avrebbe letto Schopenhauer. Dalla disamina della presenza di Schopenhauer nei Cahiers emerge, tra l'altro, la presenza della "pensée-image», che Valéry interpreta in modo non tanto empirista quanto ontologico; parimenti appare una riflessione sulla volontà di tipo determinista prossima a quella di Schopenhauer. A mano a mano che Valéry si addestra nell'osservazione del proprio funzionamento mentale, i parallelismi con la riflessione del filosofo si intensificano rivelando un'affinità nella loro comune idea di essere vivente non disgiunta dal ricorso conoscitivo alla sensorialità, come nel tomo VII dei Cahiers allorché affronta il tema della rappresentazione, i meccanismi di affioramento involontario dell'Idea e lo stupore e gli effetti di sorpresa nella conoscenza, tutti a suo avviso di derivazione schopenhaueriana.

La terza parte «Figures et figures de l'être. La pensée de Schopenhauer dans les œuvres de Valéry» (pp. 171-252), estende l'analisi a un corpus più esteso di opere di Valéry quali le Cycle Teste, le Cycle Léonard, la Jeune Parque, Eupalinos, le Cimetière marin e testi sulla musica e l'architettura. Qui Kokay, affermando che «ces œuvres manifestent à plusieurs reprises des notions formulées par Schopenhauer, ou du moins des notions très semblables à celles développées par lui» (p. 173), mostra il limite implicito della sua operazione critica, dai tratti talora didascalici ma non priva di ragioni d'interesse, ovvero il fatto che la parte dimostrativa dei suoi assunti presupponga la matrice "certamente" schopenhaueriana di talune idee di Valéry quando poi nell'affermarlo spesso prudenzialmente (e opportunamente) egli mantiene la forma possibilista del condizionale che propende per la probabilità più che per l'assoluta certezza, mentre altrove non esita a scrivere "C'est exactement la pensée de Schopenhauer» (p. 195). Quanto lo studio di Kokay ripropone è quindi riconducibile al complesso rapporto tra filosofia e poesia, dove, anche nel caso di un poeta-pensatore come Valéry, l'estensione degli assunti filosofici all'interpretazione dei testi poetici si scontra con l'irriducibilità dello scarto poetico al concetto, ovvero con la non sovrapponibilità di due linguaggi a volte tematicamente affini, ma sostanzialmente e formalmente differenti. 